\title{
Du findest Deinen Weg!
}

\section{Tanja Kühnle}

Dipl.-Biol., Managing Editor

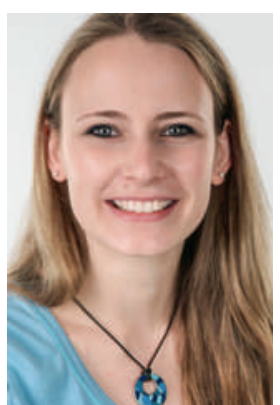

Als kleines Mädchen hatte ich unendlich viele Berufswünsche: Mal wollte ich als Stewardess um die Welt fliegen und so alle Länder dieser Erde kennenlernen. Mal wollte ich meine Kreativität ausleben und eine Ausbildung zur Goldschmiedin machen oder Grafikdesign studieren. Dann träumte ich davon, Kinderärztin zu werden und so den Kleinsten und Schwächsten helfen zu können. Und als Franziska van Almsick 1992 zwei Silbermedaillen bei den Olympischen Spielen in Barcelona gewann, dachte ich über eine Karriere als Profisportlerin nach - aber nur ganz kurz, denn ich schwimme zwar gern, doch leider fehlt mir jede Form von sportlichem Talent.

\section{Eigentlich hatte ich geplant, nach meiner Diplomarbeit eine Promotion zu beginnen.}

Verwirklicht habe ich keine dieser vielen Ideen, nicht mal im Ansatz. Doch beschweren will ich mich nicht, denn das Schicksal hat mich beruflich auf einen ganz wunderbaren Weg geführt ... Darf ich mich Ihnen kurz vorstellen? Mein Name ist Tanja Kühnle. Ich bin die Nachfolgerin von Annette Eichholtz als Managing Editor bei der Schweizerischen Ärztezeitung.

$\mathrm{Zu}$ meinem Beruf bin ich über viele Umwege gekommen, denn ich habe weder Germanistik noch Journalismus oder Kommunikationswissenschaften studiert - auch nicht Medizin. Ich hatte mir als Studienfach zunächst Jura ausgesucht, was leider gar nicht zu mir passte, so dass ich nach ein paar Semestern entschied, zur Biologie zu wechseln. Während meiner Diplomarbeit habe ich dann an der Universität zufällig einen Vortrag der Reihe «Finde Deinen Weg Karrierechancen für Naturwissenschaftler» gehört. An diesem Tag berichteten Mitarbeiter eines Medizinverlags aus Stuttgart darüber, wie man als Naturwissenschaftler ins Verlagswesen einsteigen kann: nämlich über ein sogenanntes Volontariat, eine eineinhalbjährige Ausbildung zur Fachredakteurin.

Eigentlich hatte ich geplant, nach meiner Diplomarbeit eine Promotion $\mathrm{zu}$ beginnen. Eine Stelle hatte ich schon. Aber sosehr ich die Molekularbiologie mochte, eine klassische Karriere als Laborleiterin konnte ich mir nicht vorstellen. Da ich jedoch schon immer gern geschrieben hatte und mich medizinische Themen interessierten, bewarb ich mich schliesslich bei dem Stuttgarter Verlag - und hatte Glück: Schon kurze Zeit später trat ich ein Volontariat in der Fachzeitschriftenredaktion an.

Nach meiner Ausbildung zog es mich dann nach Heidelberg ans Deutsche Krebsforschungszentrum (DKFZ), wo ich in der Pressestelle gearbeitet und unter anderem für das Wissenschaftsmagazin einblick geschrieben habe. Der einblick berichtet über die neusten Erkenntnisse der DKFZ-Forscher und wird vorwiegend von Krebspatienten und deren Angehörigen gelesen. Ganz besonders am Herzen lag mir der einblick for kids, eine Sonderausgabe für Kinder, die uns alle vor eine grosse Herausforderung gestellt und dann grossen Anklang gefunden hat. Sogar Guido Westerwelle, der damalige Aussenminister der Bundesrepublik Deutschland, hat uns zu diesem Heft gratuliert.

Vor der Geburt unseres Sohnes bin ich dann zu meinem Mann in die Schweiz gezogen und war nun, nach eineinhalb Jahren "Mama-Sein», auf der Suche nach einer passenden Stelle im Raum Basel. Der Rest der Geschichte ist Ihnen bekannt ...

Wie Sie sehen, verlief meine «Karriere» alles andere als gradlinig. Insbesondere der Studienfachwechsel von Jura zu Biologie hat mir viele schlaflose Nächte berei-

\section{Schon kurze Zeit später trat ich ein Volontariat in der Fachzeitschriftenredaktion an.}

tet. Und auch die Entscheidung gegen eine Promotion und für den Verlag habe ich mir damals nicht leicht gemacht. Ich hatte Angst, einen Fehler zu machen, zu viele Türen zuzuschlagen. Rückblickend war das völlig unbegründet. Denn es gibt so unendlich viele Möglichkeiten und nicht den «einen», den «richtigen» Weg. 